\title{
Comparison of Radiation Exposure of the Surgeon in Minimally Invasive Treatment of Osteoporotic Vertebral Fractures - Radiofrequency Kyphoplasty versus Balloon Kyphoplasty with Cement Delivery Systems (CDS)
}

\author{
Vergleich der Strahlenbelastung des Operateurs bei \\ der minimalinvasiven Versorgung osteoporotischer \\ Wirbelkörperfrakturen - Radiofrequenz-Kyphoplastie versus \\ Ballon-Kyphoplastie mit Cement-delivery-Systems (CDS)
}

Authors

Steffen Reißberg ${ }^{1}$, Lina Lüdeke ${ }^{2}$, Michael Fritsch ${ }^{3}$

Affiliations

1 Institute of Neuroradiology, Helios-Klinikum Berlin-Buch, Berlin, Germany

2 Institute of Diagnostic Radiology and Neuroradiology, Dietrich-Bonhoeffer-Klinikum Neubrandenburg, Neubrandenburg, Germany

3 Department of Neurosurgery, Dietrich-BonhoefferKlinikum Neubrandenburg, Neubrandenburg, Germany

Key words

kyphoplasty, radiation safety, technical aspects, spine

received 09.12 .2018

accepted 25.06.2019

Bibliography

DOI https://doi.org/10.1055/a-0969-2117

Published online: 6.11.2019

Fortschr Röntgenstr 2020; 192: 59-64

(c) Georg Thieme Verlag KG, Stuttgart · New York

ISSN 1438-9029

Correspondence

Dr. Steffen Reißberg

Institut für Neuroradiologie, Helios-Klinikum Berlin-Buch,

Schwanebecker Chaussee 50, 13125 Berlin, Germany

Tel.: ++ 49/30/9 40153700

steffen.reissberg@helios-gesundheit.de

\section{ABSTRACT}

The aim of the present study was to compare the radiation exposure of the surgeon when using two different kyphoplasty systems for the minimally invasive treatment of osteoporotic vertebral body fractures. There was a preliminary investigation study by a Belgian working group from the ORAMED project (2010), which served as the basis and showed a dose reduction for the surgeon when using a balloon kyphoplasty system with cement delivery systems (CDS).
Materials and Methods A bipedicular balloon kyphoplasty system (Medtronic $\mathrm{GmbH}$ ) with CDS and a unipedicular radiofrequency kyphoplasty system (StabiliT, DFine Europe GmbH) were used in solitary fractures in the thoracolumbar junction in 20 patients each. The patient groups were relatively homogeneous with a mean age of 76.9 years for balloon kyphoplasty and 75 years for radiofrequency kyphoplasty. As expected, the proportion of woman was higher in both groups. The mean BMI value was higher in the radiofrequency kyphoplasty group, and the patient with the highest BMI was also in this group. The workflows were defined in three steps. The working time and the fluoroscopic time were measured in the individual work steps and the dose was measured over all work steps by TLD chips (thermoluminescence detector) on the forehead, on the X-ray apron, on both wrists and on the left ankle. The dose area product was registered for the entire procedure.

Results In step 2, the main differences were found in working time and fluoroscopy time in transit. The difference was due to the bipedicular puncture for balloon kyphoplasty and the change of the working cannula, while only a unipedicular puncture was needed in radiofrequency kyphoplasty. The total fluoroscopy time over all procedures was three times longer than in balloon kyphoplasty and this was also reflected in the dose area product, which was more than twice that. The measured surface doses for the lenses were four times higher in balloon kyphoplasty. For the left wrist, the values for balloon kyphoplasty were about 8 times higher.

Conclusion Overall, from a radiophysical perspective, the use of a unipedicular kyphoplasty system must be recommended. Should balloon kyphoplasty be used for medical reasons, all radiation protection products (lead gloves, lead glass, radiation protection goggles and $\mathrm{CDS}$ ) should be used, the surface doses for both hands must be detected by a ring dosimeter and the lens dose must be recorded and documented by a TLD on the radiation protection goggles. 


\section{Key Points:}

- Unipedicular kyphoplasty systems would be the better options for radiation protection reasons.

- Specific medical indications may justify the use of a bipedicular kyphoplasty system on a case-by-case basis.

- The use of a ballon kyphoplasty system without CDS is no longer recommended.

- When using a bipendicular kyphoplasty system, the surface doses for the hands and the lens must be documented.

\section{Citation Format}

- Reißberg S, Lüdeke L, Fritsch M. Comparison of Radiation Exposure of the Surgeon in Minimally Invasive Treatment of Osteoporotic Vertebral Fractures - Radiofrequency Kyphoplasty versus Balloon Kyphoplasty with Cement Delivery Systems (CDS). Fortschr Röntgenstr 2020; 192: 59-64

\section{ZUSAMMENFASSUNG}

Ziel der vorliegenden Untersuchung war der Vergleich der Dosisbelastung des Operateurs bei der Verwendung 2 verschiedener Kyphoplastie-Systeme zur minimalinvasiven Versorgung von osteoporotischen Wirbelkörperfrakturen. Es lag eine Voruntersuchung einer belgischen Arbeitsgruppe aus dem ORAMED-Projekt (2010) vor, die als Grundlage diente und eine Dosisreduktion für die Augenlinsen und die linke Hand bei der Verwendung eines Ballon-Kyphoplastie-Systems mit Cement-delivery-Systems (CDS) für den Operateur zeigte. Material und Methoden Verwendet wurden ein bipedikuläres Ballon-Kyphoplastie-System (Fa. Medtronic GmbH) mit CDS und ein unipedikuläres Radiofrequenz-Kyphoplastie-System (StabiliT, Fa. DFine Europe $\mathrm{GmbH}$ ) bei solitären Frakturen im thorakolumbalen Übergang bei jeweils 20 Patienten. Die Patientenkollektive waren mit einem mittleren Alter von 76,9 Jahren für die Ballon-Kyphoplastie und 75 Jahren für die Radiofrequenz-Kyphoplastie relativ homogen. Der Frauenan- teil war erwartungsgemäß in beiden Gruppen höher. Der Mittelwert für den BMI war bei der Gruppe der Radiofrequenz-Kyphoplastie höher und auch der Patient mit dem größten BMI-Wert war in dieser Gruppe. Die Arbeitsabläufe wurden in 3 Arbeitsschritte definiert. Die Arbeitszeit und die Durchleuchtungszeit (DLZ) wurden in den einzelnen Arbeitsschritten gemessen und die Oberflächendosis über alle Arbeitsschritte durch TLD-Chips (Thermolumineszenzdetektor) an der Stirn, auf der Röntgenschürze, an beiden Handgelenken und am linken OSG gemessen. Das Dosisflächenprodukt wurde für die gesamte Prozedur registriert.

Ergebnisse Im Arbeitsschritt 2 fanden sich die wesentlichen Unterschiede zwischen beiden Systemen in Arbeitszeit und Durchleuchtungszeit. Der Unterschied war bedingt durch die bipedikuläre Punktion für die Ballon-Kyphoplastie und den Wechsel der Arbeitskanüle, während bei der RadiofrequenzKyphoplastie nur eine unipedikuläre Punktion benötigt wurde. Die Gesamtdurchleuchtungszeit über alle Arbeitsschritte war bei der Ballon-Kyphoplastie 3-mal so lang; dies spiegelte sich auch im Dosisflächenprodukt wider, welches mehr als doppelt so hoch war. Die gemessenen Oberflächendosen für die Augenlinsen waren bei der Ballon-Kyphoplastie im Mittel 4-mal höher. Für das linke Handgelenk lagen die Werte bei der Ballon-Kyphoplastie etwa 8-mal höher.

Schlussfolgerung Insgesamt muss aus strahlenhygienischer Sicht die Empfehlung zur Verwendung eines unipedikulären Kyphoplastie-Systems gegeben werden. Sollte die Ballon-Kyphoplastie aus medizinischen Gründen zur Anwendung kommen, sind sämtliche Strahlenschutzmittel (Bleihandschuhe, Bleiglasscheibe, Strahlenschutzbrille und CDS) zu nutzen und die Oberflächendosen für beide Hände durch Ringdosimeter und die Linsendosis durch ein TLD an der Strahlenschutzbrille zu erfassen und zu dokumentieren.

\section{Introduction}

The use of minimally invasive surgical techniques under fluoroscopy guidance in orthopedics and trauma surgery has become increasingly important in recent years. In particular, the transpedicular treatment of vertebral body fractures with dorsal stabilization and/or kyphoplasty are examples of radiation exposure of staff and surgeons [1].

The goal of this study was to determine the surgeon's radiation exposure in the treatment of osteoporotic vertebral body fractures via kyphoplasty using two different kyphoplasty systems. Balloon kyphoplasty is currently the most commonly used minimally invasive method. Radiofrequency kyphoplasty represents an alternative method which promises to be less invasive and to lower the surgeon's radiation exposure [2].

As the age profile of the population in industrialized countries changes, the probability of a symptomatic vertebral body compression fracture increases. Affected patients have a lower quality of life as a result of limited mobility. This is associated with an increasing number of cardiovascular diseases and thus an increase in mortality of approximately $23 \%$ compared to the unaffected control group [3-6]. Minimally invasive vertebral body stabilization procedures using cement to stabilize the vertebral body and reduce patient pain as quickly as possible were developed to accelerate the mobilization of patients often with multimorbidity.

In a preliminary study as part of the EU project ORAMED (Optimization of Radiation Protection of Medical Staff), a Belgian working group was able to show a dose reduction for the surgeon in bipedicular kyphoplasty procedures with and without use of a cement application system (CDS) [7]. Therefore, the radiation exposure was able to be reduced by approximately $70 \%$ for the left hand and by $20 \%$ for the eye lens. The personal dose ( $\mathrm{Hp} \mathrm{0.07)}$ was determined at defined locations.

The personal dose ( $\mathrm{Hp} \mathrm{0.07)} \mathrm{corresponds} \mathrm{to} \mathrm{the} \mathrm{equivalent}$ dose at a depth of $0.07 \mathrm{~mm}$ at the location where the personal dosimeter is worn. It is measured by partial-body dosimeters (e. g. ring dosimeter). It provides an estimate for the local skin dose and the lens dose. 
The equivalent dose $\mathrm{H}$ cannot be directly measured but rather corresponds to the biological effect in connection with the absorbed dose. The effect of the radiation on biological tissue with the same absorbed dose depends on the type of radiation.

\section{Materials and Methods}

A balloon kyphoplasty system (Medtronic $\mathrm{GmbH}$ ) and a radiofrequency kyphoplasty system (StabiliT, DFine Europe $\mathrm{GmbH}$ ) were used in this comparative study.

Balloon kyphoplasty typically requires bipedicular access to the vertebral body. The puncture cannula must be replaced by a working cannula via a K-wire. The working cannula is then used to perform the procedure to restore the height of the vertebral body with balloons. The cavities in the vertebral body are then filled with cement that ideally interlocks with the adjacent spongiosa. In balloon kyphoplasty, cement applicators are inserted bilaterally via the working cannulas. Cement is applied manually within the fluoroscopy field. The CDS allows the cement to be applied from outside the fluoroscopy field. The length of the application tube is maximal $120 \mathrm{~cm}$ and the cement is applied manually by means of water hydraulics.

Radiofrequency kyphoplasty requires only a single unipedicular access to the vertebral body since use of a special flexible osteotome in the center of the vertebral body ensures that the cement is distributed in the vertebral body. The puncture cannula also functions as the working cannula and does not need to be replaced. A control unit is used to apply the cement via water hydraulics. The cement application can be controlled at a distance of up to $3.0 \mathrm{~m}$ from the fluoroscopy field by means of an operating element. The cement is activated by a special activation element on the application needle just prior to insertion into the vertebral body.

40 patients with a fracture in the thoracolumbar junction or in the lumbar spine were randomly treated with one of the kyphoplasty systems ( $\triangleright$ Table 1 ). The average age of the patients in the balloon kyphoplasty group was 76.9 years (min. 57 years, max. 95 years) and the ratio of men to women was 9 to 11. The average age of the patients in the radiofrequency kyphoplasty group was 75 years (min. 54 years, max. 89 years) and the ratio of men to women was 7 to 13 .

The size and weight of each patient were registered and used to determine BMI. The average BMI was 27.6 (min. 26.2, max. 38.8 ) for the balloon kyphoplasty patient group and 29.3 (min. 24, max. 40.6) for the radiofrequency kyphoplasty group.

Both systems were already in use at the hospital prior to the study (starting in 2011). In the period from April 2013 to February 2014, osteoporotic vertebral body fractures were treated under local anesthesia on a monoplanar angiography system (Siemens Artis zee). The interventions were performed by the same surgeon with many years of experience in both balloon kyphoplasty and radiofrequency kyphoplasty. The angiography system is equipped on-site with undertable radiation protection strips, overtable lead strips, and a mobile lead glass screen. The footswitch for triggering radiation is connected to the system via WLAN so that triggering can be performed at any distance from

\begin{tabular}{|l|c|c|}
\hline & balloon kyphoplasty & radiofrequency kyphoplasty \\
\hline Th11 & 0 & 1 \\
\hline Th12 & 5 & 7 \\
\hline L1 & 7 & 5 \\
\hline L2 & 4 & 5 \\
\hline L3 & 2 & 1 \\
\hline L4 & 2 & 1 \\
\hline total & 20 & 20 \\
\hline
\end{tabular}

the fluoroscopy field. AP and lateral projections were used. In the AP projection the $X$-ray tube was tilted maximal $15^{\circ}$ in the cranial or caudal direction. The $X$-ray tube was positioned under the table for the AP projection and to the right of the patient for the lateral projection.

Prior to every examination, TLD chips (thermoluminescence detector) were attached at defined locations to determine the surface dose. TLD chips were attached to the forehead between the eyes (lens dose), to the inner surface of the left and right wrist, to the X-ray apron at the level of the costal arch, and to the left ankle. The left ankle was facing the fluoroscopy field, i. e., the left half of the examiner's body was the side near the tube.

The distances from the fluoroscopy field were marked on the floor for each procedure (balloon kyphoplasty $1.20 \mathrm{~m}$ and radiofrequency kyphoplasty $2.40 \mathrm{~m}$ ) to clearly define the distances as determined by the room size.

The dose area product for the entire procedure was determined and recorded

The TLD chips were evaluated as quickly as possible at the Landesanstalt für Personendosimetrie und Strahlenbelastung Berlin (LPS Berlin). The background radiation (measuring point) was $0.009+/-0.004 \mathrm{mSv}$. The decision threshold was $0.02 \mathrm{mSv}$ and the detection limit was $0,03 \mathrm{mSv}$. The confidence level of the measurement uncertainty was $+/-95 \%(k=2)$.

3 work steps were defined in order to be able to compare the working times and fluoroscopy times for each application.

Work step 1 was the planning and setting of the projections for the intervention. The examiner stands to the left of the patient with the left body side facing the X-ray tube. The lead glass screen can be used.

In radiofrequency kyphoplasty, work step 2 included the unipedicular vertebral body puncture under fluoroscopy and the application of the osteotome. The examiner again stands to the left of the patient. It is not possible to use the lead glass screen during puncture of the vertebral body and the examiner's hand must be in the fluoroscopy field during fluoroscopy in order to ensure correct determination of the puncture angle and correct positioning with respect to the vertebral arch. For balloon kyphoplasty, this work step included bipedicular puncture of both vertebral arches, replacement of the working cannulas, and bilateral application of the balloons under fluoroscopy. Also in this case the examiner 
- Table 2 Average working times and fluoroscopy times for the individual work steps in balloon and radiofrequency kyphoplasty in minutes.

\begin{tabular}{|c|c|c|c|c|c|c|}
\hline & planning & puncture & cement & planning & puncture & cement \\
\hline & \multicolumn{3}{|c|}{ time in minutes } & \multicolumn{3}{|c|}{ fluoroscopy time in minutes } \\
\hline balloon kyphoplasty & 2.4 & 19.3 & 8.9 & 0.75 & 4.3 & 2.1 \\
\hline radiofrequency kyphoplasty & 2.4 & 7.9 & 8.4 & 0.63 & 1.3 & 0.82 \\
\hline
\end{tabular}

stands to the left of the patient table and the examiner's hands are partially in or very close to the fluoroscopy field.

The last and $3^{\text {rd }}$ work step for both systems was cement application and final imaging on 2 planes. In this work step the examiner was able to be $1.20 \mathrm{~m}$ from the fluoroscopy field for balloon kyphoplasty and $2.40 \mathrm{~m}$ for radiofrequency kyphoplasty when using a CDS.

\section{Results}

On average, the patients in the balloon kyphoplasty group were 2 years older, while the group of radiofrequency kyphoplasty patients included a higher percentage of women. With respect to BMI, the patients in both groups were overweight on average. Both groups included 3 patients in obesity class I. 3 patients in the balloon kyphoplasty group and 2 patients in the radiofrequency kyphoplasty group were in obesity class II and 1 patient in the radiofrequency kyphoplasty group was in obesity class III.

The fluoroscopy times for the individual work steps are shown in $\mathbf{r}$ Table $\mathbf{2}$.

There were no significant differences with respect to working time and fluoroscopy time in work step 1. Both the working time and the fluoroscopy time were higher by a factor of 2 to 3 in work step 2 for the patients in the balloon kyphoplasty group. Work step 3 included a longer fluoroscopy time for the patients in the balloon kyphoplasty group.

The average dose area product was 2352,1 $\mu \mathrm{Gym}^{2}$ (min. $820.5 \mu \mathrm{Gym}^{2}$, max. $4844.3 \mu \mathrm{Gym}^{2}$ ) for balloon kyphoplasty and $925.9 \mu \mathrm{Gym}^{2}$ (min. 100.6 $\mu \mathrm{Gym}^{2}$, max. $1570.8 \mu \mathrm{Gym}^{2}$ ) for radiofrequency kyphoplasty.

The average total fluoroscopy time for all work steps was 07:32 minutes for balloon kyphoplasty and 02:31 minutes for radiofrequency kyphoplasty.

The average personal dose values are shown in $>$ Table 3.

\section{Discussion}

Considering the BMI in both kyphoplasty groups, a higher radiation dose for the surgeon is to be expected when performing radiofrequency kyphoplasty based on the higher BMI values in the radiofrequency kyphoplasty group. The patient with the highest BMI of 40.6 was in the radiofrequency kyphoplasty group and also had the highest dose area product value in this group $\left(1570.8 \mu \mathrm{Gym}^{2}\right)$ as expected. However, the highest individual $\left(4844.3 \mu \mathrm{Gym}^{2}\right)$ and total $\left(2352.1 \mu G \mathrm{gm}^{2}\right)$ dose area product val- ues for all work steps were in the balloon kyphoplasty group. As the BMI values show, this was not due to patient characteristics but rather primarily to the longer fluoroscopy times needed for balloon kyphoplasty especially in work step 2 with the bipedicular access and the replacement of the puncture cannula with the working cannula. The total fluoroscopy time for all work steps was three times longer in balloon kyphoplasty and this is reflected in the dose area product which was twice as high on average.

For the surface dose and lens dose ( $\triangleright$ Fig. 1, 2), the greatest differences were seen with respect to the wrists and especially the left wrist. Since the TLDs have a lower detection limit of $0.03 \mathrm{mSv}$ and the dose values for radiofrequency kyphoplasty are close to $0 \mathrm{mSv}$, the measured values were 0 for the lens in two cases and 0 for the right wrist in one case. These values were used in the statistical analysis even though they correspond to a systematic error.

The reason for the higher dose values for the left wrist is the position of the surgeon to the left of the patient so that the left side of the surgeon's body was facing the direct radiation field. On average, the measured surface doses for the lenses were four times higher in balloon kyphoplasty. The values for the left wrist were almost 8 times higher in balloon kyphoplasty. Although the effect of the greater distance from the radiation source during cement application in radiofrequency kyphoplasty is positive, the relevant dose difference is the result of the unipedicular access in work step 2 .

The hypothesis that a unipedicular procedure has clear dose advantages for the surgeon compared to a bipedicular procedure was able to be confirmed in this study. This method-based difference had not yet been proven in this manner in earlier studies. Numerous studies have addressed dose reduction methods using various cement application techniques or the advantage of using radiation protection equipment during puncture and cement application in the direct radiation field [8-10]. The determination of the local dose for individuals participating in surgery has also been the objective of studies [11, 12]. The comparison of various kyphoplasty systems under consideration of radiation dose for the surgeon is new and has not yet been examined in any studies. Ultimately, reducing the surface dose by reducing the time spent in the direct radiation field is the more effective means of radiation protection that must be further optimized by the use of radiation protection equipment. The inverse square law can be better applied in the case of cement application using water hydraulics in radiofrequency kyphoplasty.

A stationary X-ray system equipped on-site with the corresponding technical radiation protection equipment that is 
- Table 3 Mean personal dose values in mSv for balloon kyphoplasty and radiofrequency kyphoplasty.

\begin{tabular}{|l|l|l|l|l|l|}
\hline dose in $\mathbf{m S v}$ & forehead & on the X-ray apron & right wrist & left wrist & left ankle \\
\hline balloon kyphoplasty & 0.217 & 0.67 & 1.249 & 3.908 & 0.154 \\
\hline $\begin{array}{l}\text { radiofrequency } \\
\text { kyphoplasty }\end{array}$ & 0.05 & 0.137 & 0.198 & 0.523 & 0.06 \\
\hline
\end{tabular}

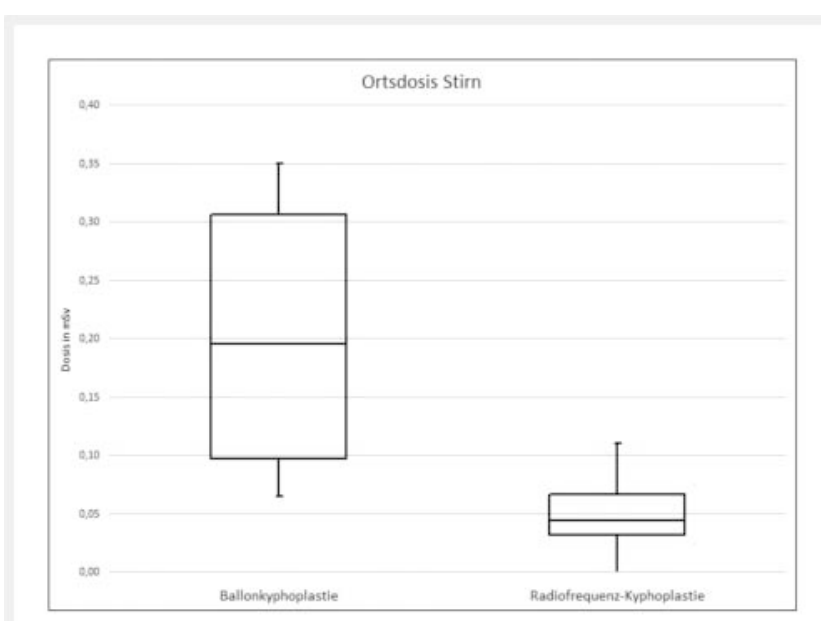

- Fig. 1 Box plot of the dose values measured on the forehead during balloon and radiofrequency kyphoplasty.

usually not present for procedures in the operating room with mobile systems (C-arm) was used in this study. Therefore, additional studies using mobile $\mathrm{X}$-ray systems should be performed to obtain reliable values for the real radiation dose for the surgeon in the operating room.

If the results from the ORAMED study are included, use of balIoon kyphoplasty without CDS and radiation protection equipment can no longer be accepted with respect to a reduction of the surface dose particularly for the left hand and the eyes. The surface dose values must also be measured by ring dosimeters and dosimeters on the radiation safety goggles, particularly in light of the lowering of the annual limit for the eye lenses from $150 \mathrm{mSv}$ to $20 \mathrm{mSv}$ in the new X-ray Ordinance dated 1/1/2019.

\section{Conclusion}

Use of a unipedicular kyphoplasty system must be recommended for radiation hygiene purposes. If balloon kyphoplasty is used for medical reasons, all radiation protection equipment (lead gloves, lead glass screen, and radiation protection goggles) are to be used and the surface dose for both hands must be recorded and documented by a ring dosimeter and the lens dose by a TLD on the radiation protection goggles. It is no longer acceptable to use balloon kyphoplasty without a CDS.

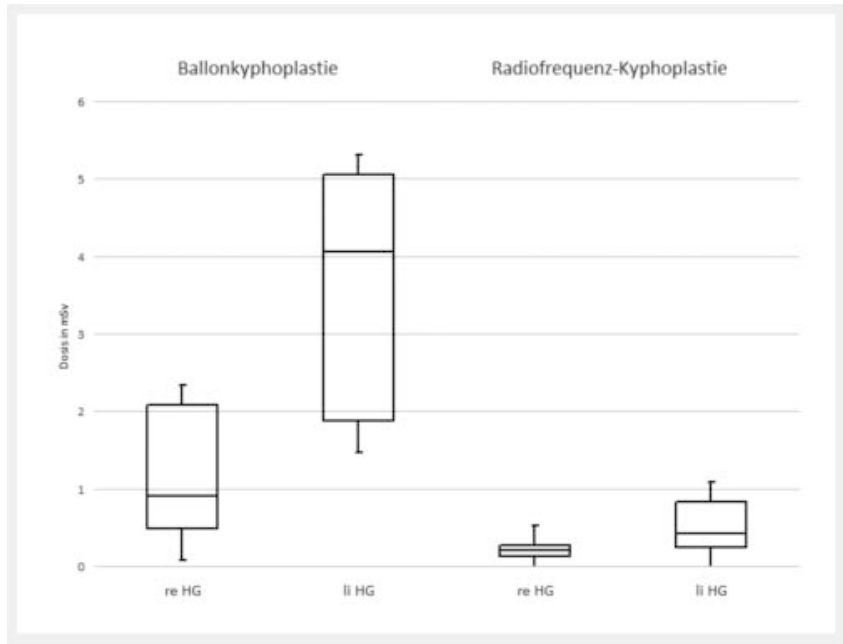

- Fig. 2 Box plot - comparison of the measured dose values for both wrists during balloon and radiofrequency kyphoplasty systems.

\section{Conflict of Interest}

The authors declare that they have no conflict of interest.

\section{References}

[1] Yu E, Khan SN. Does less invasive spine surgery result in increased radiation exposure? A systematic review. Clin Orthop Relat Res 2014; 472: $1738-1748$

[2] Drees P, Kafchitsas K, Mattyasovszky S et al. Die Radiofrequenz-Kyphoplastie - Eine innovative Methode zur Behandlung von osteoporotischen Wirbelkörperkompressionsfrakturen. J Miner Soffwechs 2010; 17 (Sonderheft: 15-19

[3] Schlaich C, Minne HW, Bruckner T et al. Reduced pulmonary function in patients with spinal osteoporotic fractures. Osteoporosis Int 1998; 8: 261-267

[4] Gold DT. The clinical impact of vertebral fractures: quality of life in woman with osteoporosis. Bone 1996; 18: 185-189

[5] Silverman SI, Minshall ME, Shen W et al. The relationship of health-related quality of life to prevalent and incident vertebral fractures in postmenopausal woman with osteoporosis: results from the Multiple Outcomes of Raloxifene Evaluation Study. Arthritis Rheum 2001; 44: 2611-2619

[6] Kado DM, Browner WS, Palermo L et al. Vertebral fractures and mortality in older woman: aprospective study. Arch Intern Med 1999; 159: 12151220

[7] Struelens L, Krim S, Vanhavere F. Extremity Doses of Medical Staff for Complex Interventional Procedures and in Nuclear Medicine ExDos. Final report 2010. 
[8] Li YY, Huang T], Cheng CC et al. Comparing radiation exposure during percutaneus vertebroplasty using one- vs. two-fluoroscopic technique. BMC Musculoskeletal Disorders 2013; 14: 38. doi:10.1186/1471-247414-38

[9] Schils F, Schoojans W, Struelens L. The surgeon's real dose exposure during ballon kyphoplasty procedure and evaluation oft he cement delivery system: a prospective study. Eur Spine J 2013; 22: 1758-1764. doi:10.1007/s00586-013-2702-z

[10] Zhang GQ, Gao YZ, Chen SL et al. Significantly reduced radiation dose to operators during percutaneous vertebroplasty using a new cement delivery device. BMC Musculoskeletal Disorders 2014; 15: 260-266. doi:10.1186/1471-2474-15-260

[11] Libischer M, Knoch T, Keuler A et al. Ortsdosismessung während der Kyphoplastie - Vorschläge zur Reduktion der Strahlendosis von Operateur und OP-Personal. Fortschr Röntgenstr 2005; 177 - VO_4109: doi:10.1055/s-2005-867860

[12] Schütz U, Beer M, Wild A et al. Strahlenschutz bei C-Bogen-gestützten Wirbelsäulenprozeduren in Orthopädie und Unfallchirurgie. OUP 2016; 4: 224-237. doi:10.3238/oup.2016.0224-237 